\title{
Integrating Combined First Trimester Screening for Preeclampsia into Routine Ultrasound Examination
}

\author{
Integration von kombiniertem Ersttrimester-Screening auf \\ Präeklampsie in die routinemäßige Ultraschalluntersuchung
}

(c) (1) $\ominus$

Authors

Fabienne Trottmann, Anne Elena Mollet, Sofia Amylidi-Mohr, Daniel Surbek, Luigi Raio, Beatrice Mosimann

Affiliation

Department of Obstetrics and Feto-maternal Medicine, University Hospital Insel Bern, University of Bern, Bern, Switzerland

Key words

obstetrics, sonography, pregnancy, preeclampsia, epidemiology

Schlüsselwörter

Geburtshilfe, Ultraschall, Schwangerschaft, Präeklampsie, Epidemiologie

received

accepted after revision

22.6. 2021

Bibliography

Geburtsh Frauenheilk 2022; 82: 333-340

DOI 10.1055/a-1534-2599

ISSN 0016-5751

(C) 2022. The Author(s).

This is an open access article published by Thieme under the terms of the Creative Commons Attribution-NonDerivative-NonCommercial-License, permitting copying and reproduction so long as the original work is given appropriate credit. Contents may not be used for commercial purposes, or adapted, remixed, transformed or built upon. (https://creativecommons.org/licenses/by-nc-nd/4.0/)

Georg Thieme Verlag KG, Rüdigerstraße 14,

70469 Stuttgart, Germany

Correspondence

Dr. Fabienne Trottmann, MD

Department of Obstetrics and Feto-maternal Medicine, University Hospital Insel Bern, University of Bern

Friedbühlstrasse 19, 3010 Bern, Switzerland

fabienne.trottmann@insel.ch

\section{ABSTRACT}

Introduction The Fetal Medicine Foundation (FMF) London has developed a first trimester screening algorithm for preeclampsia (PE), based on maternal characteristics and past risk factors, mean arterial pressure (MAP), uterine artery pulsatility index (UtA-PI), and placental growth factor (PIGF). The aim of this study was to determine the feasibility of integrating PE screening into routine practice.

Material and Methods All pregnancies with a fetal crownrump length of 45-84 mm presenting to our ultrasound department between January 2014 and September 2020 were included in this analysis. Screening for PE was offered to singleton pregnancies only. The number of screening tests performed in the eligible population was assessed and the reasons for missed screenings identified with the help of the electronic clinical database. SPSS Statistics 25 and GraphPad version 8.0 for Windows were used for statistical analysis.

Results 6535 pregnancies were included, 4510 (69.0\%) of which were screened for PE. The percentage of patients being offered PE screening increased over the years from 63.1 to $96.7 \%\left(r_{s}=0.96 ; p=0.003\right)$, while the rate of screenings performed in eligible patients remained stable at a median [range] of 86.2\% [78.0-91.8\%] ( $p=n s) .2025$ (31.0\%) pregnancies were not screened for PE, 1306 (64.5\%) because they were not eligible for screening. 145 (2.2\%) women explicitly declined PE screening; their background risk was lower than that of women who accepted screening.

Conclusion Our study shows that integration of PE screening into the routine first trimester ultrasound scan is feasible and widely accepted by pregnant women and health care providers.

\section{ZUSAMMENFASSUNG}

Einleitung Die Fetal Medicine-Stiftung (FMF) in London hat einen Algorithmus für ein Ersttrimester-Screening auf Präeklampsie (PE) entwickelt, das auf maternalen Merkmalen und Risikofaktoren in der Anamnese, dem mittleren arteriellen Druck (MAP), dem Pulsatilitätsindex der A. uterina (UtA-PI) sowie dem plazentaren Wachstumsfaktor (PIGF) basiert. Ziel dieser Studie war es, die Machbarkeit einer Integration von PE-Screening in die klinische Praxis zu ermitteln.

Material und Methoden Alle Schwangerschaften mit einer fetalen Scheitel-Steiß-Länge von 45 bis $84 \mathrm{~mm}$, die sich zwischen Januar 2014 und September 2020 in der Ultraschallabteilung vorstellten, wurden in dieser Analyse aufgenommen. Ein PE-Screening wurde nur Frauen mit Einlingsschwanger- 
schaften angeboten. Die Anzahl der in der teilnahmeberechtigten Population durchgeführten Screeningtests wurde evaluiert, und die Gründe für nicht erfolgte Untersuchungen wurden mithilfe der elektronischen Datenbank der Klinik identifiziert. SPSS Statistics 25 und GraphPad Version 8.0 für Windows wurden für die statistische Analyse verwendet.

Ergebnisse Insgesamt wurden 6535 Schwangerschaften in die Studie aufgenommen, davon wurden 4510 (69,0\%) auf das Risiko einer Präeklampsie getestet. Der Prozentsatz von Patientinnen, denen PE-Screening angeboten wurde, nahm über die Jahre von 63,1 auf 96,7\% zu ( $\left.r_{s}=0,96 ; p=0,003\right)$, wohingegen der Prozentsatz der Untersuchungen, die bei infrage kommenden Patientinnen durchgeführt wurde, bei einem Mittelwert [Bandbreite] von 86,2\% [78,0-91,8\%] ( $p=n s)$ stabil blieb. 2025 (31,0\%) Schwangerschaften wurden nicht auf das PE-Risiko untersucht, davon 1306 (64,5\%), weil sie die Kriterien für ein Screening nicht erfüllten. 145 (2,2\%) Frauen lehnten ein PE-Screening explizit ab; ihr Hintergrundrisiko war niedriger als das Risko bei den Frauen, die ein PEScreening angenommen haben.

Schlussfolgerung Unsere Studie zeigt, dass die Integration von PE-Screening in routinemäßig durchgeführten Ersttrimester-Ultraschalluntersuchungen machbar ist, und dass sie von Schwangeren und Gesundheitsdienstleistern weithin akzeptiert wird.

\section{Introduction}

Preeclampsia (PE) is a multisystem disorder that affects $2-7 \%$ of all pregnancies and is associated with short- and long-term risks for both mother and child [1-4]. Delivery is still the only treatment for PE available today, however prevention is possible in high-risk pregnancies if low dose aspirin (LDA) treatment is started before 16 weeks of gestation [5]. Screening by maternal characteristics and a previous history of risk factors as proposed by many obstetric societies detects around $30 \%$ of all preterm PEs (<37 weeks) [6-12]. The Fetal Medicine Foundation (FMF) London has developed a first trimester screening algorithm combining background risk factors with placental growth factor (PIGF), mean arterial pressure (MAP) and uterine artery pulsatility index (UtA-PI). This screening identifies $75 \%$ of preterm PE cases $[6,7,13]$. The ASPRE trial (Aspirin for Evidence-Based Preeclampsia Prevention) confirmed the effectiveness of LDA in patients identified by this screening to be at risk and demonstrated a reduction of preterm PE by $62 \%$ in women who screened positive [14].

Offering first trimester screening for aneuploidies is widespread and, in many countries, it is part of routine pregnancy care $[15,16]$. In addition to screening for fetal aneuploidies, first trimester ultrasound also allows the detection of various structural fetal anomalies, and therefore first trimester screening has evolved to become the most important ultrasound exam in pregnancy [16].

The introduction of first trimester PE screening into routine pregnancy care, however, is still an ongoing process, hampered by issues such as practicability and costs. While several validation studies and, more recently, implementation studies have been published which confirm the performance of the combined PE screening algorithm, little information is yet available about the performance of first trimester PE screening in a general clinical setting $[10,12,17]$. In particular, there are no studies regarding its feasibility and women's acceptance of introducing this PE screening algorithm into the first trimester ultrasound scan. A subanalysis of the ASPRE trial investigated the reasons for accepting or declining PE screening. In this randomized controlled study, $6.8 \%$ of women declined participation for various reasons such as insufficient information and discouragement by significant others (partner, family, health professional) [18]. Reasons to participate were personal benefit, small risk, sufficient information, trust in professionals, and encouragement by others [18].

First trimester screening for fetal anomalies and aneuploidies has been offered to pregnant women for nearly two decades at our department. In 2014, we introduced combined first trimester screening for PE along with the routine first trimester ultrasound. The screening test mostly performs according to expectations in our cohort as we could demonstrate in a recently accepted publication [19]. The aim of this study was to investigate the feasibility of introducing PE screening into routine first trimester ultrasound in clinical practice.

\section{Patients and Materials}

\section{Screening methods}

We performed an observational cohort study with a prospective analysis of retrospective data. All women who attended the Center for Ultrasound and Prenatal Diagnosis of the Department of Obstetrics and Feto-maternal Medicine at University Hospital of Bern for their 11-14 weeks scan between January 2014 and September 2020 and agreed to the further use of their data were included in this study. All women with a singleton or multiple pregnancy and a fetal crown-rump length of $45-84 \mathrm{~mm}$ are routinely offered early morphological screening and first trimester combined screening for aneuploidies.

First trimester screening for aneuploidies is performed by combining maternal age with fetal nuchal translucency (NT) and the biochemical parameters "pregnancy-associated plasma protein A" (PAPP-A) and "beta human chorionic gonadotropin" ( $\beta$-HCG) $[20,21]$. All women are informed about the possibility of having additional non-invasive prenatal testing (NIPT) or an invasive procedure. As of July 2015, NIPT in the form of sequential screening for all women in whom the combined first trimester aneuploidy screening test yields a risk for trisomies $\geq 1: 1000$ is covered by health insurance in Switzerland [22]. Invasive procedures are proposed to women who have a high risk at combined aneuploidy screening (individual decision, covered by insurance if the risk in the first trimester combined screening is $>1: 380$ ), a NT $>3.5 \mathrm{~mm}$ or if fetal anomalies are detected during the scan [22]. 
In addition, for families at risk of an inherited genetic condition, invasive testing is offered after genetic counseling.

First trimester combined screening for preeclampsia (PE) has been offered to singleton pregnancies since January 2014 during the same visit. Screening for PE is performed using the algorithm developed by the Fetal Medicine Foundation (FMF) London which combines maternal characteristics and a previous history of risk factors with placental growth factor (PIGF), mean arterial pressure (MAP) and mean uterine artery pulsatility index (UtA PI). PAPP-A is included in the screening algorithm if values are available from combined screening for aneuploidies. However, if only PE screening is requested, PAPP-A is not included. Women considered at risk are prescribed LDA. Both the risks for trisomies and for PE are calculated using the algorithm provided by Viewpoint version 5.6.25.284.

\section{Patient selection}

In this analysis, we first identified the patients eligible for screening. While we introduced PE screening for patients attending our department for antenatal care from January 2014, we only offered it to patients referred from external gynecologists after publication of the ASPRE trial. Women referred before July 2017 as well as all multiple pregnancies were therefore considered not eligible for PE screening in this study. We included them in the study to assess the overall screening rate for PE. However, when analyzing the rates of acceptance, we only included the eligible group.

Combined screening for aneuploidies was not repeated if it was previously performed by a private provider and the woman was referred to our center for second opinion, and it was not offered if an invasive procedure was indicated or NIPT was performed prior to the scan. All other pregnancies were considered eligible for first trimester combined aneuploidy screening in this trial. Screening tests that were incomplete due to one or several missing parameters were included in this analysis and considered performed if the result was communicated to the patient.

To assess the acceptance of screening, we analyzed the percentage of screening tests performed in the eligible population. In pregnancies not screened for aneuploidies by combined screening in the first trimester and not screened for PE or for both, we analyzed the reasons for screenings not being performed by studying the screening records of these patients in our electronic clinical database.

\section{Data analysis}

Data collection and analysis was performed using our encrypted medical database, and information was saved using Viewpoint ${ }^{\circledR}$ software. Statistical analyses were performed with GraphPad ${ }^{\circledR}$ version 8.0 for Windows (GraphPad Software, San Diego, CA,

- Table 1 Characteristics of the study population. Comparisons are made between pregnancies which had combined screening for aneuploidies and the total study population and between pregnancies which had PE screening and the total study population. They are depicted in absolute numbers $(\mathrm{N})$ and interquartile ranges $[\mathrm{IQR}]$ or as percentages (\%). Additionally, the significance between pregnancies which had combined screening for aneuploidies and the total study population as well as the significance between pregnancies which had PE screening and the total study population are depicted in the third and fifth columns.

\begin{tabular}{|c|c|c|c|c|c|}
\hline & Total $(\mathrm{N}=6535)$ & $\begin{array}{l}\text { Aneuploidy screening } \\
(\mathrm{N}=5401)\end{array}$ & $\mathbf{p}^{\dagger}$ & $\begin{array}{l}\text { PE screening } \\
(N=4510)\end{array}$ & $\mathbf{p}^{\ddagger}$ \\
\hline $\begin{array}{l}\text { Maternal age at term } \\
\text { (median }[\mathrm{IQR}] \text { ) }\end{array}$ & $33[29-37]$ & $33[29-36]$ & n.s. & $33[29-36]$ & $p=0.005$ \\
\hline Maternal BMI (median [IQR]) & $23.2[20.9-26.5]$ & $23.2[20.9-26.5]$ & n.s. & 23.3 [20.9-26.6] & n.s. \\
\hline Gravidity (median [IQR]) & $2[1-3]$ & $2[1-3]$ & n.s. & $2[1-3]$ & n.s. \\
\hline \multicolumn{6}{|l|}{ Parity } \\
\hline $\begin{array}{l}\text { - Nulliparous } \\
\text { - Parous, no previous PE } \\
\text { - Parous, previous PE }\end{array}$ & $\begin{array}{c}3205 / 6388(50.2) \\
3015 / 6388(47.2) \\
168 / 6388(2.6)\end{array}$ & $\begin{array}{c}2738 / 5312(51.5) \\
2429 / 5312(45.7) \\
145 / 5312(2.7)\end{array}$ & $\begin{array}{l}\text { n.s. } \\
\text { n.s. } \\
\text { n.s. }\end{array}$ & $\begin{array}{c}2281 / 4450(51.3) \\
2013 / 4450(45.2) \\
156 / 4450(3.5)\end{array}$ & $\begin{array}{l}\text { n.s. } \\
p=0.046 \\
p=0.010\end{array}$ \\
\hline \multicolumn{6}{|l|}{ Ethnicity } \\
\hline $\begin{array}{l}\text { - Caucasian } \\
\text { - Other }\end{array}$ & $\begin{array}{l}4994 / 6007(83.1) \\
1013 / 6007(16.9)\end{array}$ & $\begin{array}{r}4393 / 5337(82.3) \\
944 / 5337(17.7)\end{array}$ & $\begin{array}{l}\text { n.s. } \\
\text { n.s. }\end{array}$ & $\begin{array}{r}3655 / 4506(81.1) \\
851 / 4506(18.9)\end{array}$ & $\begin{array}{l}p=0.007 \\
p=0.007\end{array}$ \\
\hline Smoking & $480 / 6282(7.6)$ & $419 / 5369(7.8)$ & n.s. & $340 / 4510(7.5)$ & n.s. \\
\hline Medical conditions* & $196 / 5352(3.6)$ & $183 / 4759(3.8)$ & n.s. & $175 / 4491(3.9))$ & n.s. \\
\hline Conception by IVF & $371 / 6370(5.8)$ & $323 / 5385(6.0)$ & n.s. & $243 / 4510(5.4)$ & n.s. \\
\hline Family history of PE & $68 / 5282(1.3)$ & $63 / 4725(1.3)$ & n.s. & $65 / 4490(1.4)$ & n.s. \\
\hline Multiple pregnancy & $331 / 6535(5.1)$ & $274 / 5401(5.1)$ & n.s. & $0 / 4510(0.0)$ & $\mathrm{p}<0.0001$ \\
\hline $\begin{array}{l}\text { Figures are given as median a } \\
{ }^{*} \text { Relevant medical history inc } \\
\mathrm{p}<0.05 \text { is considered statistic } \\
\mathrm{p}^{\ddagger} \text { : significance between preg }\end{array}$ & $\begin{array}{l}\text { erquartile ranges], figu } \\
\text { tiabetes mellitus, hype } \\
\text { nificant; } \mathrm{p}^{\dagger} \text { : Significan } \\
\text { s which had an PE scre }\end{array}$ & $\begin{array}{l}\text { arentheses are percentas } \\
\text { n, systemic lupus eryther } \\
\text { veen pregnancies which h } \\
\text { ind the total study popula }\end{array}$ & $\begin{array}{l}\text { : in vit } \\
\text { s, anti }\end{array}$ & $\begin{array}{l}\text { zation. } \\
\text { olipid syndrome. } \\
\text { eening and the total st }\end{array}$ & ulation; \\
\hline
\end{tabular}


USA) and the SPSS ${ }^{\circledR}$ statistical software package. Continuous variables were analyzed with Kruskal-Wallis or Mann-Whitney U-test, and proportions were evaluated using Fisher's exact test or $x^{2}$ test where appropriate. Correlations were searched for using the Spearman rank correlation test. Statistical significance was considered to be achieved when p was below 0.05 .

The study was approved by the Ethics Committee of the Canton of Bern.

\section{Results}

During the study period, 6535 women with 6906 fetuses attended our clinic for first trimester ultrasound screening. Patient characteristics are depicted in $\boldsymbol{\vee}$ Table $\mathbf{1}$.

\section{PE screening}

$5225(80.0 \%)$ of all included pregnancies were considered eligible for PE screening. Screening for PE was performed in 4510 (69.0\%) pregnancies, with a median [range] of 585 [500-814] screenings performed per year. The percentage of patients eligible for PE screening increased over the years from 63.1 to $96.7 \%\left(r_{s}=0.96\right.$; $p=0.003)$, as did the absolute number of tests performed per year from 2014 to 2019 ([500-814], $\left.r_{s}=0.93 ; p=0.022\right)$. The rate of PE screening performed in eligible patients remained stable at a median [range] of $86.2 \%$ [78.0-91.8\%] ( $p=$ n. s.) ( $\triangleright$ Fig. 1 a). The different reasons why no PE screening was performed in the remaining 2025 (31.0\%) pregnancies are given in > Table 2. As regards the 145 (2.2\%) patients who declined screening for PE, no significant change in these figures was noted over the years (1531 per year, $p=n . s) ..110(75.9 \%)$ of them also declined combined screening for aneuploidies while 35 (24.1\%) agreed to aneuploidy screening only.

\section{Combined screening for aneuploidies}

6070 (92.9\%) pregnancies were eligible for combined screening for aneuploidies. Screening was performed in 5401 (89.0\%) of them, which corresponds to a median [range] of 743 [684-914] tests per year. The rate of women accepting aneuploidy screening when offered remained stable during the study period at a median [range] of $90.9 \%$ [82.8-90.9\%] (p=n.s.) ( (9.5\%) women eligible for screening declined first trimester aneuploidy screening; 460 (80\%) of them accepted measurement of nuchal translucency without calculation of the combined risk for trisomies. 243 (42.3\%) women who declined aneuploidy screening accepted PE screening.

\section{Subanalysis of women declining PE screening}

Characteristics of the women who declined PE screening compared to those who accepted screening are given in $>$ Table 3 . Women who declined PE screening had a lower risk profile with regard to their BMI, their obstetric history, mode of conception, and ethnicity. Other risk factors linked to previous medical history did not differ between the women who refused and those who accepted PE screening.
- Table 2 Differential analysis of the 2025 patients who did not have a PE screening. They are depicted in absolute numbers $(\mathrm{N})$ and as percentages (\%). Additionally, the percentage of the total study population of 6535 pregnancies is depicted in the second column.

\begin{tabular}{|l|c|c|}
\hline Reason & N (\%) & $\begin{array}{l}\text { \% of total } \\
\text { population }\end{array}$ \\
\hline Not eligible (not offered) & $1306(64.5)$ & 19.9 \\
\hline - External referral before 06/2017 & $977(48.3)$ & 14.9 \\
\hline - Multiple pregnancy & $329(16.3)$ & 5.0 \\
\hline Eligible & $719(35.5)$ & 11.0 \\
\hline - 2nd opinion/pathologies & $293(14.5)$ & 4.5 \\
\hline - Language difficulties & $11(0.5)$ & 0.2 \\
\hline - LDA started before screening & $27(1.3)$ & 0.4 \\
\hline - Refused by referring OBGYN & $28(1.4)$ & 0.4 \\
\hline - Refused by patient & $145(7.2)$ & 2.2 \\
\hline - No explanation & $215(10.6)$ & 3.3 \\
\hline Total & $2025(100)$ & 31.0 \\
\hline
\end{tabular}

Figures are in numbers and percentages. LDA: low dose aspirin; OBGYN: obstetrician and gynecologist

\section{Discussion}

The results of our study demonstrate that introducing PE screening into routine practice as part of first trimester ultrasound screening is feasible and very much accepted by pregnant women and doctors. The test was performed in $86.2 \%$ of all women considered eligible for PE screening, a figure that is comparable to the 90.9\% of all women eligible for aneuploidy screening who accepted such screening. While nearly $10 \%$ of all women declined screening for aneuploidies because of the lack of consequences, only $2.2 \%$ of all women explicitly declined screening for PE ( $\vee$ Table 2). Acceptance amongst healthcare providers is also high; few referring doctors explicitly refuse PE screening for their patient ( $\triangleright$ Table 2).

PE screening was not performed in $11 \%$ of all pregnancies, mostly either due to referral for a second opinion regarding a fetal problem or for no obvious reason ( $\bullet$ Table 2 ). Our interpretation is that the involved physicians focused on the reasons for the referral and less on general screening options. However, pregnancies with increased nuchal translucency, increased risk of aneuploidies at screening and diagnosed genetic anomalies such as trisomy 13 are found to be at increased risk of preeclampsia if the pregnancy is continued [23-26]. Another explanation could be that some doctors are less convinced that PE screening is useful. As demonstrated in the SPREE trial, even though $10.3 \%$ of all patients were screen-positive using the NICE method, only $4.5 \%$ were treated with LDA, despite the national guidelines [11]. Therefore, in future we should focus on offering PE screening to women with pregnancies showing abnormalities at aneuploidy screening or on the occasion of the first trimester anomaly scan. This also emphasizes the importance of patient counseling and the education of health professionals, as their attitude towards di- 


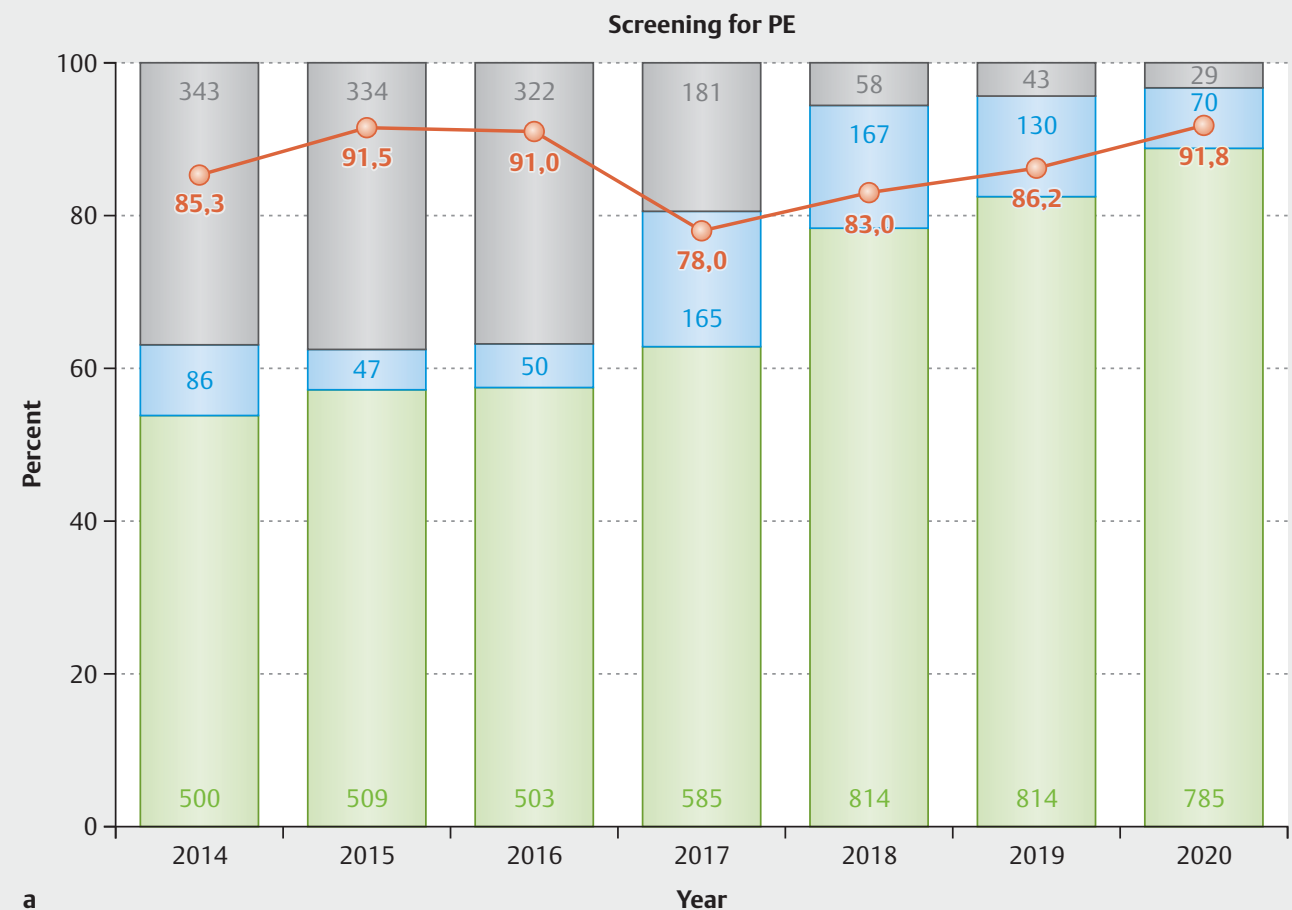

$\square$ Not eligible

$\square$ Eligible, no screening

$\square$ PE screening performed

Screening for aneuploidies

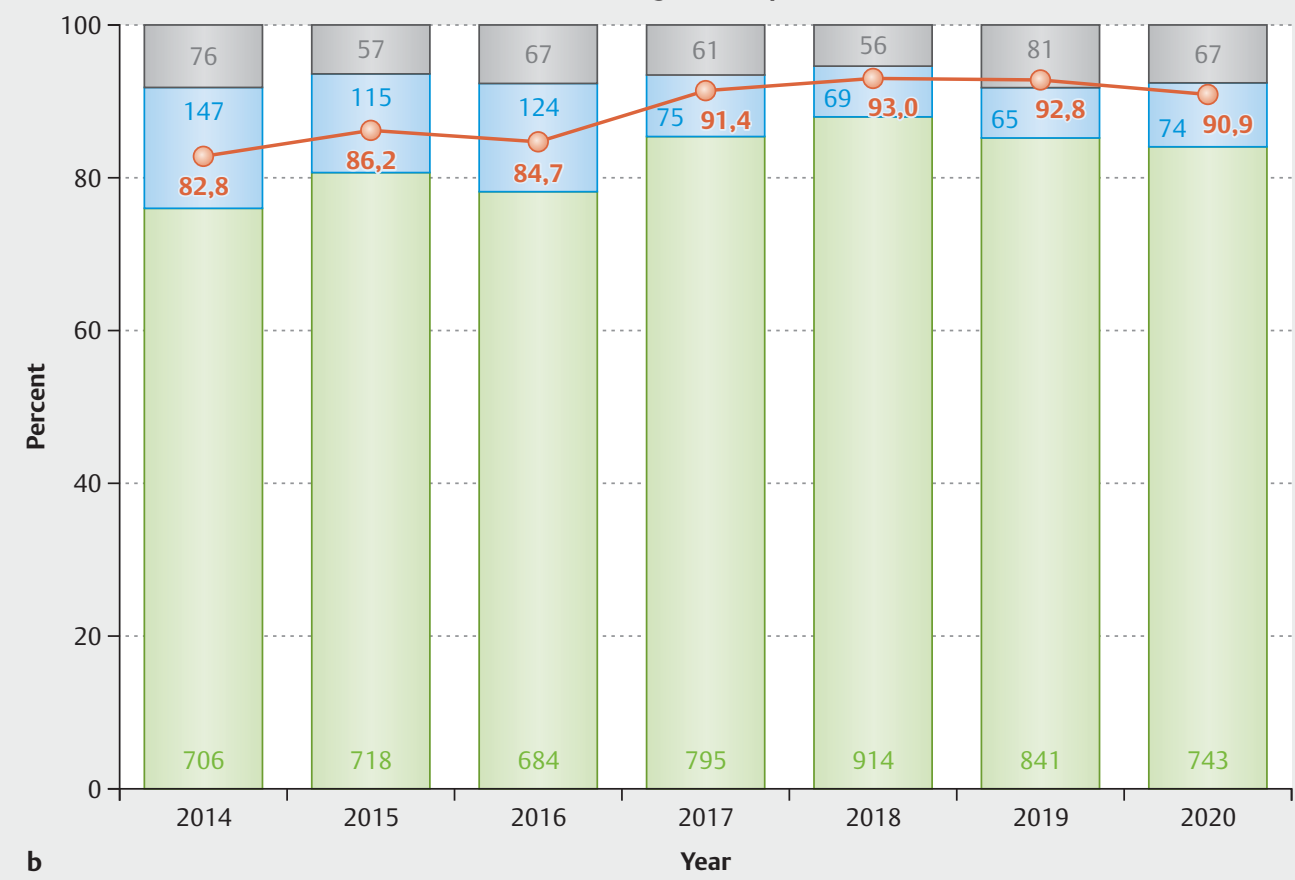

$\square$ Not eligible

$\square$ Eligible, no screening

$\square$ Aneuploidy screening performed

Fig. 1 Uptake of PE screening and combined screening for aneuploidies over the years. The numbers in the bars refer to absolute numbers and they are also displayed as percentages for each year. The rates of all women eligible for PE or aneuploidy screening who had a screening are included in red in both figures. 
- Table 3 Characteristics of the populations who declined vs. accepted screening for PE. They are depicted in absolute numbers (N) and as percentages (\%) or interquartile ranges [IQR] where applicable. In the third column, the significance between patients who accepted and those who declined PE screening with regard to specific maternal characteristics are depicted.

\begin{tabular}{|c|c|c|c|}
\hline & PE screening refused $(N=145)$ & PE screening accepted $(\mathrm{N}=4510)$ & $\mathbf{p}$ \\
\hline Maternal age at term (median [IQR]) & $33[30-36]$ & 33 [29-36] & n.s. \\
\hline Maternal BMI at 12 weeks (median [IQR]) & $22.2[20.0-24.3]$ & $23.3[20.9-26.6]$ & $p=0.0009$ \\
\hline Nulliparous & $52 / 139(37.4)$ & $2281 / 4450(51.3)$ & $p=0.0014$ \\
\hline - previous miscarriage/TOP & $10 / 139(7.2)$ & $564 / 4450(12.7)$ & n.s. \\
\hline Parous with previous PE & $0 / 139(0.0)$ & $156 / 4450(3.5)$ & $p=0.015$ \\
\hline \multicolumn{4}{|l|}{ Ethnicity } \\
\hline $\begin{array}{l}\text { - Caucasian } \\
\text { - Black/South Asian }\end{array}$ & $\begin{array}{l}91 / 102(89.2) \\
8 / 102(7.8)\end{array}$ & $\begin{array}{r}3655 / 4506(81.1) \\
557 / 4506(12.4)\end{array}$ & $\begin{array}{l}p=0.039 \\
\text { n. s. }\end{array}$ \\
\hline Smoking & $5 / 123(0.4)$ & $340 / 4510(7.5)$ & n.s. \\
\hline Medical conditions* & $0 / 83(0.0)$ & $175 / 4491(3.9)$ & n.s. \\
\hline Conception by IVF & $2 / 132(1.5)$ & $243 / 4510(5.4)$ & $p=0.047$ \\
\hline Family history of PE & $0 / 83(0.0)$ & $65 / 4490(1.4)$ & n.s. \\
\hline \multicolumn{4}{|c|}{$\begin{array}{l}\text { Figures are given as medians [IQR]; the figures in parentheses are percentages; IQR: interquartile ranges, TOP: termination of pregnancy, PE: preeclampsi } \\
\text { IVF: in vitro fertilization, n. s.: not significant. }\end{array}$} \\
\hline
\end{tabular}

agnostic tools may be reflected in their counseling and hence affect the decision taken by the patient.

The subanalysis of patients who declined PE screening in our cohort demonstrated a lower background risk than for women who accepted screening. Women who declined screening had a lower BMI, which correlates with a lower risk for PE [27, 28]. Maternal age is a risk factor for PE and trisomies; while advanced maternal age leads to an increased acceptance of aneuploidy screening, no such association was found for PE screening $[29,30]$. This can be explained by the fact that the screening rate for PE decreased with higher parity, which is linked to maternal age. In addition, more nulliparous women accepted screening, possibly because nulliparity was perceived as a risk factor, but possibly also because nulliparous women generally accept more screening tests [29,31]. Only two women who conceived with IVF declined screening and all women with a medical risk factor accepted screening. We consider this finding the result of patients being well-informed, as described by Möller et al. [32].

Availability of a screening test is a crucial factor influencing the uptake of screening. Although there are inherent differences between aneuploidy screening and PE screening, mainly regarding the possibility of prevention and treatment of the condition screened for, it is worth taking a comparative look at the uptake of first trimester aneuploidy screening, which has been extensively studied in the past. While in the UK the uptake of aneuploidy screening increased to $75 \%$ once the test was introduced into routine care, it has remained much lower in the Netherlands where screening is only offered to women older than 36 years of age $[15,16,31]$. In Scandinavian countries like Denmark and Iceland, aneuploidy screening is part of routine care and the uptake is at least $90 \%$, comparable to our setting and the uptake of aneu- ploidy screening in our cohort [33]. Trials investigating the acceptance of non-invasive prenatal testing (NIPT) with cell-free fetal DNA mostly confirmed that uptake was clearly related to reimbursement by insurance companies or the national health system $[15,34]$. Other factors affecting the uptake of aneuploidy screening include counseling, the level of maternal education and trust in the healthcare provider as well as test-specific reasons such as maternal age, religious beliefs and the availability and acceptance of termination of pregnancy [29,30,32,35-38]. To date, there are no studies published which have investigated the acceptance of first trimester combined screening for PE in the general population. One can only assume that some factors mentioned above also influence the uptake of PE screening.

Women who generally refuse any screening in pregnancy may not book an appointment for the first trimester ultrasound. However, the vast majority of pregnant women in Switzerland do, in fact, opt for first trimester ultrasound screening. Therefore, the acceptance rate in our cohort can in part be expanded to the general Swiss population. While the majority of women in our cohort who declined PE screening also declined aneuploidy screening and seemed therefore more critical of screening tests in general, many women who declined aneuploidy screening accepted PE screening. The reason for declining aneuploidy screening is mostly the fact that a positive screening test would have no consequence for the women as they would accept a child with chromosomal abnormalities. In addition, $80 \%$ of these women accepted the assessment of fetal nuchal translucency as a marker for other fetal anomalies apart from chromosomal abnormalities. 


\section{Conclusion}

In conclusion, our study demonstrates that the integration of screening for PE using the FMF algorithm into first trimester ultrasound screening is feasible and accepted by pregnant women as well as healthcare providers. Counseling of all pregnant women on the issue of preeclampsia early in pregnancy is important, including the possibility of PE screening and prevention as well as symptoms and risks, as many women are not familiar with this disease.

\section{Sources of Funding}

None.

\section{Conflict of Interest}

The authors declare that they have no conflict of interest.

\section{References}

[1] Hutcheon JA, Fellow P. Epidemiology of pre-eclampsia and the other hypertensive disorders of pregnancy. Best Pract Res Clin Obstet Gynaecol 2011; 25: 391-403. doi:10.1016/j.bpobgyn.2011.01.006

[2] Mol BW], Roberts CT, Thangaratinam S et al. Preeclampsia. Lancet 2016; 387: 999-1011. doi:10.1016/S0140-6736(15)00070-7

[3] Poon LC, Shennan A, Hyett JA et al. The International Federation of Gynecology and Obstetrics (FIGO) initiative on pre-eclampsia: A pragmatic guide for first-trimester screening and prevention. Int J Gynaecol Obstet 2019; 145 (Suppl. 1): 1-33. doi:10.1002/ijgo.12802

[4] Sibai B, Dekker G, Kupferminc M et al. Pre-eclampsia. Lancet 2005; 365: 785-799. doi:10.1016/S0140-6736(05)17987-2

[5] Bujold E, Roberge S, Lacasse $Y$ et al. Prevention of Preeclampsia and Intrauterine Growth Restriction With Aspirin Started in Early Pregnancy A Meta-Analysis. Obstet Gynaecol 2010; 116: 402-414. doi:10.1097| AOG.0b013e3181e9322a

[6] Akolekar R, Syngelaki A, Poon L et al. Competing risks model in early screening for preeclampsia by biophysical and biochemical markers. Fetal Diagn Ther 2013; 33: 8-15. doi:10.1159/000341264

[7] Wright D, Tan MY, O'Gorman N et al. Predictive performance of the competing risk model in screening for preeclampsia. Am J Obstet Gynecol 2019; 220: 199.e1-199.e13. doi:10.1016/j.ajog.2018.11.1087

[8] O'Gorman N, Wright D, Syngelaki A et al. Competing risks model in screening for preeclampsia by maternal factors and biomarkers at 1113 weeks gestation. Am J Obstet Gynecol 2016; 214: 103.e1-103.e12. doi:10.1016/j.ajog.2015.08.034

[9] Wright D, Syngelaki A, Akolekar R et al. Competing risks model in screening for preeclampsia by maternal characteristics and medical history. Am J Obstet Gynecol 2015; 213: 62.e1-62.e10. doi:10.1016/j. ajog.2015.02.018

[10] Poon LC, Rolnik DL, Tan MY et al. ASPRE trial: incidence of preterm preeclampsia in patients fulfilling ACOG and NICE criteria according to risk by FMF algorithm. Ultrasound Obstet Gynecol 2018; 51: 738-742. doi:10.1002/uog.19019

[11] Tan MY, Wright D, Syngelaki A et al. Comparison of diagnostic accuracy of early screening for pre-eclampsia by NICE guidelines and a method combining maternal factors and biomarkers: results of SPREE. Ultrasound Obstet Gynecol 2018; 51: 743-750. doi:10.1002/uog.19039
[12] Rolnik DL, Wright D, Poon LC et al. ASPRE trial: performance of screening for preterm pre-eclampsia. Ultrasound Obstet Gynecol 2017; 50: 492495. doi:10.1002/uog. 18816

[13] Mosimann B, Amylidi-Mohr SK, Surbek D et al. First trimester screening for preeclampsia - a systematic review. Hypertens Pregnancy 2020; 39: 1-11. doi:10.1080/10641955.2019.1682009

[14] Rolnik DL, Wright D, Poon LC et al. Aspirin versus Placebo in Pregnancies at High Risk for Preterm Preeclampsia. N Engl J Med 2017; 377: $613-$ 622. doi:10.1056/NEJMoa1704559

[15] Public Health England. NHS Fetal Anomaly Screening Programme (FASP): programme overview (01.01.2013). Accessed February 01, 2021 at: https://www.gov.uk/guidance/fetal-anomaly-screeningprogramme-overview\#screening-test-downs-edwards-and-pataussyndromes

[16] Tringham GM, Nawaz TS, Holding S et al. Introduction of first trimester combined test increases uptake of Down's syndrome screening. Eur J Obstet Gynecol Reprod Biol 2011; 159: 95-98. doi:10.1016/j. ejogrb.2011.07.039

[17] Mosimann B, Pfiffner C, Amylidi-Mohr S et al. First Trimester Combined Screening for Preeclampsia and Small for Gestational Age - a Single Centre Experience and Validation of the FMF Screening Algorithm. Swiss Medical Weekly 2017; 147: w14498. doi:10.4414/smw.2017.14498

[18] Nikčević AV, Dodd Z, Prior J et al. Reasons for accepting or declining participation in the ASPRE trial: A qualitative study with women at high risk of preterm pre-eclampsia. Prenat Diag 2019; 39: 1127-1135. doi:10.1002/pd.5554

[19] Amylidi-Mohr S, Kubias ], Neumann S et al. Reducing the Risk of Preterm Preeclampsia: Comparison of Two First Trimester Screening and Treatment Strategies in a Single Centre in Switzerland. Geburtshilfe Frauenheilkd 2021. doi:10.1055/a-1332-1437

[20] Kagan KO, Wright D, Valencia C et al. Screening for trisomies 21, 18 and 13 by maternal age, fetal nuchal translucency, fetal heart rate, free betahCG and pregnancy-associated plasma protein-A. Hum Reprod 2008; 23: 1968-1975. doi:10.1093/humrep/den224

[21] Santorum M, Wright D, Syngelaki A et al. Accuracy of first-trimester combined test in screening for trisomies 21,18 and 13 . Ultrasound $\mathrm{Ob}$ stet Gynecol 2017; 49: 714-720. doi:10.1002/uog.17283

[22] Ochsenbein N, Burkhardt T, Raio L. Pränatale nicht-invasive Risikoabschätzung fetaler Aneuploidien; Expertenbrief No 52. sggg.ch. 03/ 2018. Accessed February 01, 2021 at: https://www.sggg.ch/fileadmin/ user_upload/20180411_52_Praenatale_nicht-invasive_ Risikoabschaetzung_fetaler_Aneuploidien_07032018.pdf

[23] Baer R, Currier R, Norton M. Obstetric, Perinatal, and Fetal Outcomes in Pregnancies With False-Positive Integrated Screening. Obest Gynaecol 2014; 123: 603-609. doi:10.1097/AOG.0000000000000145

[24] Krispin E, Kushnir A, Shemer A et al. Abnormal Nuchal Translucency Followed By Normal Microarray Analysis Is Associated With Placental Pathology-Related Complications. Prenat Diagn 2021; 41: 855-860. doi:10.1002/pd.5896

[25] Wali S, Wild M. Maternal complications of fetal triploidy: a case report. BMJ Case Rep 2020; 13: e236950. doi:10.1136/bcr-2020-236950

[26] Dotters-Katz SK, Humphrey WM, Senz KL et al. Trisomy 13 and the risk of gestational hypertensive disorders: a population-based study. J Matern Fetal Neonatal Med 2018; 31: 1951-1955. doi:10.1080/ 14767058.2017.1332037

[27] Mostello D, Kallogjeri D, Tungsiripat R et al. Recurrence of preeclampsia: effects of gestational age at delivery of the first pregnancy, body mass index, paternity, and interval between births. Am J Obstet Gynecol 2008; 199: 55.e1-55.e7. doi:10.1016/j.ajog.2007.11.058

[28] Robillard P-Y, Dekker G, Scioscia M et al. Increased BMI has a linear association with late-onset preeclampsia: A population-based study. PLoS One 2019; 14: e0223888. doi:10.1371/journal.pone.0223888 
[29] Poon CF, Tse WC, Kou KO et al. Uptake of noninvasive prenatal testing in chinese women following positive down syndrome screening. Fetal Diagn Ther 2015; 37: 141-147. doi:10.1159/000365811

[30] Shahhosseini Z, Arabi H, Salehi A et al. Factors Affecting Improved Prenatal Screening: A Narrative Review. Glob J Health Sci 2016; 8: 160-165. doi:10.5539/gjhs.v8n5p160

[31] Gitsels JT, Verhoeven PS, Manniën J et al. Factors affecting the uptake of prenatal screening tests for congenital anomalies; a multicentre prospective cohort study. BMC Pregnancy Childbirth 2014; 14: 264. doi:10.1186/1471-2393-14-264

[32] Aune I, Möller A. ‘I want a choice, but I don't want to decide’-A qualitative study of pregnant women's experiences regarding early ultrasound risk assessment for chromosomal anomalies. Midwifery 2012; 28: 1423. doi:10.1016/j.midw.2010.10.015

[33] Ekelund CK, Petersen OB, Skibsted L et al. First-trimester screening for trisomy 21 in Denmark: implications for detection and birth rates of trisomy 18 and trisomy 13. Ultrasound Obstet Gynecol 2011; 38: 140-144. doi:10.1002/uog.8929
[34] Gadsbøll K, Petersen OB, Gatinois V. Current use of noninvasive prenatal testing in Europe, Australia and the USA: A graphical presentation. Acta Obstet Gynecol Scand 2020; 99: 722-730. doi:10.1111/aogs.13841

[35] Van Den Berg M, Timmermans DRM, Ten Kate LP et al. Are pregnant women making informed choices about prenatal screening? Genet Med 2005; 7: 332-338. doi:10.1097/01.gim.0000162876.65555.ab

[36] Chiang $\mathrm{HH}$, Chao MY, Yuh YS. Informed choice of pregnant women in prenatal screening tests for Down's syndrome. J Med Ethics 2006; 32: 273-277. doi:10.1136/jme.2005.012385

[37] Müller MA, Bleker OP, Bonsel G] et al. Women's opinions on the offer and use of nuchal translucency screening for Down syndrome. Prenat Diagn 2006; 26: 105-111. doi:10.1002/pd.1344

[38] De-Kun L, Karlberg K, Wi S et al. Factors influencing women's acceptance of prenatal screening tests. Prenat Diagn 2008; 28: 1136-1143. doi:10.1002/pd.2142 